\title{
Non-productive adsorption of bacterial $\beta$-glucosidases on lignins is electrostatically modulated and depends on the presence of fibronection type III-like domain
}

\author{
Viviam M. da Silva ${ }^{a}$, Anderson S. de Souza ${ }^{a}$, Djanira R. Negrão ${ }^{b}$, Igor Polikarpov ${ }^{c}$, \\ Fabio M. Squina ${ }^{\mathrm{d}}$, Mario de Oliveira Neto ${ }^{\mathrm{b}}$, João R.C. Muniz ${ }^{\mathrm{c}}$, Wanius Garcia ${ }^{\mathrm{a}, *}$ \\ ${ }^{a}$ Centro de Ciências Naturais e Humanas (CCNH), Universidade Federal do ABC (UFABC), Santo André, SP, Brazil

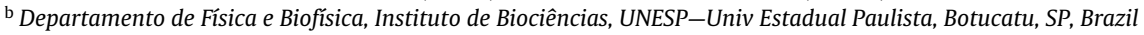 \\ ' Instituto de Física de São Carlos (IFSC), Universidade de São Paulo (USP), São Carlos, SP, Brazil \\ ${ }^{\mathrm{d}}$ Laboratório Nacional de Ciência e Tecnologia do Bioetanol (CTBE), Centro Nacional de Pesquisa em Energia e Materiais (CNPEM), Campinas, SP, Brazil
}

\section{A R T I C L E I N F O}

\section{Article history:}

Received 16 December 2015

Received in revised form 11 February 2016

Accepted 12 February 2016

Available online 16 February 2016

\section{Keywords:}

$\beta$-Glucosidases

Thermotoga petrophila

Hyperthermostable

Lignin

Fibronectin type III-like domain

\begin{abstract}
A B S T R A C T
Non-productive adsorption of cellulases onto lignins is an important mechanism that negatively affects the enzymatic hydrolysis of lignocellulose biomass. Here, we examined the non-productive adsorption of two bacterial $\beta$-glucosidases (GH1 and GH3) on lignins. The results showed that $\beta$-glucosidases can adsorb to lignins through different mechanisms. GH1 $\beta$-glucosidase adsorption onto lignins was found to be strongly $\mathrm{pH}$-dependent, suggesting that the adsorption is electrostatically modulated. For GH3 $\beta$ glucosidase, the results suggested that the fibronectin type III-like domain interacts with lignins through electrostatic and hydrophobic interactions that can partially, or completely, overcome repulsive electrostatic forces between the catalytic domain and lignins. Finally, the increase of temperature did not result in the increase of $\beta$-glucosidases adsorption, probably because there is no significant increase in hydrophobic regions in the $\beta$-glucosidases structures. The data provided here can be useful for biotechnological applications, especially in the field of plant structural polysaccharides conversion into bioenergy and bioproducts.
\end{abstract}

(c) 2016 Elsevier Inc. All rights reserved.

\section{Introduction}

Lignocellulose biomass is a complex material composed of cellulose, hemicellulose, and lignin with an approximate ratio of $2: 1: 1$, which provides a useful starting feedstock for industrial processes $[1,2]$. Cellulose is a recalcitrant biopolymer composed of linear chains of D-glucose linked by $\beta$-1,4-glycosidic bonds, whereas hemicelluloses are linear or branched heteropolysaccharides [1]. The third main component of the biomass, lignin, is an aromatic complex polymer composed of phenylpropane units, that is, guaiacyl propanol $(G)$, syringyl propanol (S), and p-hydroxyphenyl propanol $(\mathrm{H})[3,4]$. The lignin composition varies from plant to plant, and the proportion of $\mathrm{G}$ and $\mathrm{S}$ units differ significantly in softwood and hardwood [3]. Softwood lignin is principally composed of $\mathrm{G}$ units, while both $\mathrm{G}$ and $\mathrm{S}$ units are present in hard-

\footnotetext{
* Corresponding author at: Av. dos Estados 5001, Bairro Bangu, Santo André, SP CEP 09210-580, Brazil.

E-mail address: wanius.garcia@ufabc.edu.br (W. Garcia).
}

wood. Furthermore, $\mathrm{H}$ units in minor amounts, associated with $\mathrm{G}$ and $S$ units, are also present in grasses and compression wood lignin [3].

The bioconversion of lignocellulose biomass into bioethanol normally involves three main steps: (i) a pretreatment to decrease substrate recalcitrance and partially fractionate the biomass, (ii) enzymatic hydrolysis of the cellulose and hemicellulose to hexoses (as glucose) and pentoses, and (iii) fermentation of simple sugars into ethanol. Several pretreatment technologies are currently employed to remove selectively hemicellulose and lignin from the lignocellulose biomass [2,5-7]. For example, untreated sugarcane bagasse contains about $35 \%$ of cellulose and similar amounts of hemicellulose (25\%) and lignin (22\%). After acid pretreatment using $1 \% \mathrm{H}_{2} \mathrm{SO}_{4}$, most of the hemicellulose fraction was removed (25-7.8\%), however, the lignin relative percentage in the sample increased slightly (22-30\%). Then, after basic pretreatment using $\mathrm{NaOH}$, under concentrations between $0.5 \%$ and $2 \%$, the lignin relative percentage decreased progressively from $30 \%$ to $10 \%$ [2]. 


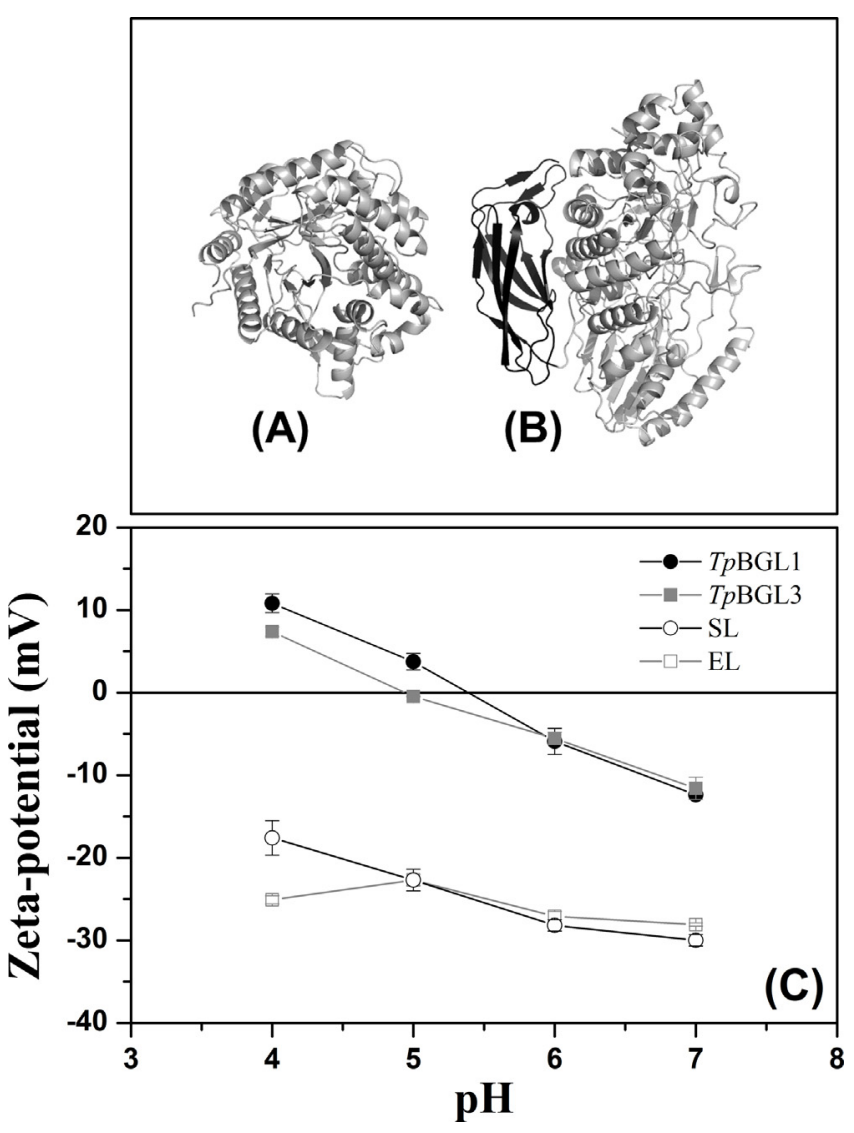

Fig. 1. Three-dimensional models of the $\beta$-glucosidases from Thermotoga petrophila and zeta-potential analysis. (A) $\beta$-Glucosidase GH1 from T. petrophila (TpBGL1). (B) $\beta$-Glucosidase GH3 from T. petrophila (TpBGL3). The C-terminal FnIII-like domain is highlighted in black. The three-dimensional models of the TpBGL1 and TpBGL3 were built by SWISS Model Server [35] using as template the available structures of the $\beta$-glucosidases from Thermotoga maritima (TmBGL1, PDB 1OIN, 99\% sequential identity) [14] and Thermotoga neapolitana (TnBGL3, PDB $2 \times 41,88 \%$ sequential identity) [16], respectively. (C) Zeta-potential of the $\beta$-glucosidases (TpBGL1 and TpBGL3) and lignin preparations (SL and EL) as a function of $\mathrm{pH}$.

The complete enzymatic hydrolysis of cellulose to glucose requires at least three types of enzymes working synergistically: endoglucanases (EC 3.2.1.4) that randomly cleave the $\beta-1,4-$ glycosidic linkages of cellulose, cellobiohydrolases (EC 3.2.1.91) which cleave off cellobiose units from the reducing or nonreducing end of cellulose chain, and $\beta$-glucosidases (EC 3.2.1.21) responsible for hydrolysis of the released cellobiose to glucose [8-10]. Endoglucanases and cellobiohydrolases are frequently inhibited by cellobiose, therefore, $\beta$-glucosidases are essential to avoid the decrease the hydrolysis rates of cellulose over time due to cellobiose accumulation [10].

The presence of residual lignin after pretreatments may affect negatively the enzymatic hydrolysis of cellulose to glucose. Cellulases bind to lignin, deactivating the enzymes and reducing the overall enzymatic activities $[3,4,11]$. In this study, we examined the non-productive adsorption of two $\beta$-glucosidases from Thermotoga petrophila $[12,13]$, belonging to the families $\mathrm{GH} 1$ and $\mathrm{GH} 3$, on the lignin preparations from both sugarcane (grasses) and eucalyptus (hardwood). These two $\beta$-glucosidases (TpBGL1 and TpBGL3) are enzymes with potential for applications in the field of plant structural polysaccharides conversion into bioenergy and bioproducts [12]. TpBGL1 has a common $(\beta / \alpha)_{8}$-barrel structure, while TpBGL3 is arranged in three distinct domains (Fig. 1) [13-15]. The $\mathrm{N}$-terminal domain is an $(\alpha / \beta)_{8}$ triose phosphate isomerase (TIM) barrel, followed by a five-stranded $\alpha / \beta$ sandwich domain, and the
C-terminal domain has a fibronectin type III fold (FnIII-like domain) [16-18].

\section{Materials and methods}

\subsection{Materials}

Imidazole, kanamycin, LB medium, isopropyl- $\beta$-D-thiogalactopyranoside (IPTG), nickel-nitrilotriacetic acid resin (Ni-NTA) and 4-nitrophenyl- $\beta$-Dglucopyranoside ( $p N P G$ ) were purchased from Sigma-Aldrich. Protein standards used as sodium dodecyl sulfate-polyacrylamide gel electrophoresis (SDS-PAGE) markers were purchased from Sigma. All chemicals and reagents used in this study were of the highest purity analytical grade.

\subsection{Expression and purification of recombinant $\beta$-glucosidases}

The expression and purification of recombinant $\beta$-glucosidases were carried out as described previously with minor modifications [13]. Briefly, 1 L of LB medium containing kanamycin $(50 \mu \mathrm{g} / \mathrm{mL})$, inoculated with Escherichia coli BL21(DE3) containing the expression plasmid construct, was incubated at $37^{\circ} \mathrm{C}$ in shake flasks until attaining an optical density of 0.5 at $600 \mathrm{~nm}$. IPTG was added to a final concentration of $0.5 \mathrm{mM}$, and incubation continued at $37^{\circ} \mathrm{C}$ for approximately $4 \mathrm{~h}$. After incubation, the cells were immediately harvested by centrifugation at $5000 \times g$ for $20 \mathrm{~min}$ at $4{ }^{\circ} \mathrm{C}$, resuspended in $20 \mathrm{mM}$ acetate-borate-phosphate buffer adjusted at $\mathrm{pH} 7.4$, and ruptured by sonication. The suspension was then centrifuged at $5000 \times \mathrm{g}$ for $20 \mathrm{~min}$ at $4{ }^{\circ} \mathrm{C}$ to separate the cell debris. The supernatant was then heat treated at $70^{\circ} \mathrm{C}$ during $30 \mathrm{~min}$, to precipitate heat-labile proteins, and centrifuged again at $5000 \times g$ for $20 \mathrm{~min}$ and $4{ }^{\circ} \mathrm{C}$. Finally, the supernatant containing the recombinant $\beta$ glucosidase ( $T p B G L 1$ or TpBGL3) was applied to a nickel-affinity column equilibrated with $20 \mathrm{mM}$ acetate-borate-phosphate buffer adjusted at pH 7.4. The recombinant $\beta$-glucosidase was eluted from the column with the same buffer containing $150 \mathrm{mM}$ imidazole. The purity of the final products was verified by $15 \%$ SDS-PAGE. The resulting $\beta$-glucosidases were exhaustively dialyzed in $20 \mathrm{mM}$ acetate-borate-phosphate buffer adjusted at $\mathrm{pH} 7.4$ for elimination of imidazole. The concentrations of the recombinant $\beta$-glucosidases were determined by UV absorbance at $280 \mathrm{~nm}$ using a theoretical extinction coefficient based on the amino acid composition. The extinction coefficients $(\varepsilon)$ were calculated for the monomers using the ProtParam tool [19] The theoretical coefficients employed were $\varepsilon_{280 \mathrm{~nm}}=121,240 \mathrm{M}^{-1} \mathrm{~cm}^{-1}$ for TpBGL1 and $\varepsilon_{280 \mathrm{~nm}}=102,930 \mathrm{M}^{-1} \mathrm{~cm}^{-1}$ for TpBGL3. The final $\beta$-glucosidases were stored at $4{ }^{\circ} \mathrm{C}$ and used until five days after the purification.

\subsection{Preparation of lignins from sugarcane (SL) and eucalyptus (EL)}

The lignin preparations from sugarcane and Eucalyptus spp. were isolated as described previously [20]. Briefly, lignins were precipitated from Kraft black liquors at pH 5 as described below. For sugarcane, the Kraft black liquors were oven-dried at $30^{\circ} \mathrm{C}$ till become powder. For Eucalyptus ssp., the Kraft black liquors ( $\mathrm{pH} 14$ ) were heated at $55-65^{\circ} \mathrm{C}$. Subsequently, the $\mathrm{pH}$ values of the liquors were slowly acidified with $3 \mathrm{M} \mathrm{H}_{2} \mathrm{SO}_{4}$. After reaching the desired $\mathrm{pH}$, the liquors were incubated undisturbed during $12 \mathrm{~h}$ in the dark at room temperature. After the incubation period, the supernatants were discarded and the solid lignins were collected, dried at $55-60^{\circ} \mathrm{C}$, and stored at room temperature and isolated from interaction with light.

\subsection{Electrophoretic light scattering (ELS)}

ELS measurements were used to determine the average zeta-potential $(\zeta)$ of the $\beta$-glucosidases and lignin preparations, which were collected using a Zetasiser nano-ZS at $20^{\circ} \mathrm{C}$ [21]. The zeta-potential were measured using fixed concentrations of enzymes (TpBGL1 and TpBGL3) and lignin preparations (SL and EL) of $1 \mathrm{mg} / \mathrm{mL}$ in $20 \mathrm{mM}$ acetate-borate-phosphate buffer adjusted to the different $\mathrm{pH}$ values. This instrument measures the electrophoretic mobility $\left(\mu_{\mathrm{e}}\right)$ and converts the value to a zeta-potential ( $\mathrm{mV}$ ) through Henryís equation: $\mu_{\mathrm{e}}=[2 \varepsilon \zeta F(\kappa a)] / 3 \eta$, where $\varepsilon$ is the dielectric constant of water and $\eta$ is the viscosity [21]. Furthermore, $F(\kappa a)$ is the Henryís function, which was calculated through the Smoluchowski approximation with $F(\kappa a)=1.5$. The isoelectric point is given by the $\mathrm{pH}$ value at which the zetapotential is approximately zero.

\section{5. $\beta$-Glucosidases adsorption}

Adsorption analyses were performed by pulling down $\beta$-glucosidases, after incubation with different lignins concentrations, and measuring its residual enzymatic activity in the supernatants [18]. The adsorptions of the $\beta$-glucosidases, TpBGL1 or TpBGL3, to lignins were conducted with $6 \mu \mathrm{M}$ of enzyme in $20 \mathrm{mM}$ acetate-borate-phosphate buffer adjusted to different $\mathrm{pH}$ values, and different lignin preparations (SL or EL) at concentrations varying from 0 to $25 \mathrm{mg} / \mathrm{mL}$. The samples (vol. $1 \mathrm{~mL}$ ) were incubated at $20^{\circ} \mathrm{C}$ or $70^{\circ} \mathrm{C}$ for $2 \mathrm{~h}$ under continuous agitation and subsequently centrifuged at $14,000 \times \mathrm{g}$ for $20 \mathrm{~min}$. The $\beta$-glucosidase activity in the supernatant was measured on pNPG as described below. $\beta$ glucosidases $(6 \mu \mathrm{M})$ also were incubated with lignins $(15 \mathrm{mg} / \mathrm{mL})$ in the presence of surfactant ( $1 \%$ Triton X-100). Controls lacking $\beta$-glucosidases or lignin preparations 
were used as reference. For each analysis, two independent experiments were done with enzymes purified in different days. Each independent experiment was done in triplicate, and the averaged values are reported. In addition, the free $\beta$-glucosidases content in the supernatant (after incubation with different lignin concentrations) were determined employing the method described by Bradford [22]. The Bradford assays were carried out in triplicate.

\section{6. $\beta$-Glucosidase activity}

The standard enzymatic assay for $\beta$-glucosidase activity was performed according to previously described method [12,23]. Briefly, $100 \mathrm{ng}$ of enzyme, $40 \mu \mathrm{L}$ of buffer solution adjusted at different $\mathrm{pH}$ values ( $\mathrm{pH} 6$ for TpBGL1 and $\mathrm{pH} 4$ for TpBGL3) were used and $50 \mu \mathrm{L}$ of $1 \mathrm{mM} 4$-nitrophenyl- $\beta$-D-glucopyranoside ( $p N P G$ ) was used as substrate. Following incubation at $70^{\circ} \mathrm{C}$ during $4 \mathrm{~min}$, the reaction was stopped by addition of $100 \mu \mathrm{L}$ of $1 \mathrm{M} \mathrm{Na}_{2} \mathrm{CO}_{3}$ and the releasing of $p$-nitrophenol was monitored colorimetrically at $405 \mathrm{~nm}$ using a microplate reader. One unit of $\beta$-glucosidase activity was defined as the amount of enzyme that released $p$-nitrophenol at rate of $1 \mu \mathrm{mol} \mathrm{m^{-1 }}$ under standard conditions. All $\beta$-glucosidase assays were performed in triplicate, and the averaged values are reported.

\section{Results}

\subsection{Influence of $\mathrm{pH}$ on the net charge of the $\beta$-glucosidases and lignins}

Zeta-potential, which is a measurement of the charge that a molecule acquires in particular environment, is an important parameter for understanding electrostatic colloidal dispersion $[13,21]$. In order to better understand the influence of $\mathrm{pH}$ on the net charge, zeta-potential of the $\beta$-glucosidases and lignin preparations were determined as a function of $\mathrm{pH}$ (Fig. 1C). As can be seen in Fig. 1C, the net charge on $\beta$-glucosidases (TpBGL1 and TpBGL3) is affected by the $\mathrm{pH}$ as recently demonstrated [13]. The enzymes can become more negatively or positively charged due to the loss or gain of protons, respectively. At $\mathrm{pH} 7$ and 6, both $\beta$ glucosidases acquire very similar negative charges, while at $\mathrm{pH} 4$ the $\beta$-glucosidases acquire positive charge. Likewise, the net charge of sugarcane lignin (SL) and eucalyptus lignin (EL) preparations are also $\mathrm{pH}$-dependent, however, both acquire negative charges in the entire studied pH range (Fig. 1C). Previous studies showed that lignins isolated from others sources also acquired negative charges at $\mathrm{pH}$ values below 7 [24,25]. For SL preparation, the negative charges were found to increase with increasing of $\mathrm{pH}$ value. At $\mathrm{pH} 4$, the negative charge was significantly higher in EL preparation when compared to SL preparation.

\subsection{Influence of $\mathrm{pH}$ on the $\beta$-glucosidases adsorption to lignins}

The adsorption of $\beta$-glucosidases to different lignin preparations were analyzed as a function of $\mathrm{pH}$ at $20^{\circ} \mathrm{C}$. Fig. 2 shows the adsorption of TpBGL1 ( $6 \mu \mathrm{M})$ as a function of the sugarcane lignin (SL) concentration at different $\mathrm{pH}$ values. For $\mathrm{pH}$ values of 7 and 6 , the results showed very low adsorption of TpBGL1 on the SL at concentrations up to about $25 \mathrm{mg} / \mathrm{mL}$ (Fig. $2 \mathrm{~A}$ and B). At pH 4, only a low adsorption of TpBGL1 was observed. The supernatant residual $\beta$-glucosidase activity remained around $70 \%$ even at the highest SL concentration used in our experiment, indicating low capacity of TpBGL1 binding to the SL at pH 4 (Fig. 2C). The adsorption of TpBGL1 as a function of the eucalyptus lignin (EL) concentration at different $\mathrm{pH}$ values is also shown in Fig. 2. At pH 7 and 6, the adsorption of TpBGL1 is very low, even at high concentrations of EL (Fig. 2D and E). However, at $\mathrm{pH} 4$ very strong adsorption of TpBGL1 on the EL can be observed at concentrations above $1 \mathrm{mg} / \mathrm{mL}$ (Fig. 2F). In addition, the free TpBGL1 content in the supernatant was also monitored as a function of the SL and EL concentrations (Supplemental Fig. 1) employing the method described by Bradford [22]. At pH 7 and 6 were not observed significant changes in TpBGL1 content even at high concentrations of SL and EL. However, at pH 4 significant changes in the protein concentrations were observed. At $\mathrm{pH} 4$ the free TpBGL1 content in the supernatant was reduced dramatically at EL concentrations above $1 \mathrm{mg} / \mathrm{mL}$. These results are in agreement with the $\beta$-glucosidase activities described above.

The adsorption of TpBGL3 $(6 \mu \mathrm{M})$ as a function of the SL concentration at different $\mathrm{pH}$ values is given in Fig. 3. At all $\mathrm{pH}$ values, the TpBGL3 enzymatic activity in the supernatant decreased significantly with the increase of SL concentrations applied to the solutions, indicating strong adsorption of TpBGL3 on the SL. At the highest SL concentration used in our experiment, the supernatant relative residual activities observed at all $\mathrm{pH}$ values were between $10 \%$ and $30 \%$ (Fig. 3A, B and C). Fig. 3 also shows the adsorption of TpBGL3 as a function of the EL concentration at different $\mathrm{pH}$ values. At all $\mathrm{pH}$ values, the results showed strong adsorption of TpBGL3 on the EL. At pH 6 and 7, the supernatant relative residual activities of $30 \%$ were observed at the highest EL concentration used. At $\mathrm{pH} 4$ very strong adsorption of TpBGL3 on the EL at concentrations above $1 \mathrm{mg} / \mathrm{mL}$ can be observed (Fig. 3F). At pH 4 and for higher EL concentrations the relative residual activity measured for the supernatant was of about $10 \%$. In addition, the free TpBGL3 content in the supernatant was also monitored as a function of the SL and EL concentrations (Supplemental Fig. 2). At all pH values, the free TpBGL3 content in the supernatant showed a progressively reduction with increasing lignins concentration. These results are in agreement with the $\beta$-glucosidase activities described above. Our data are in agreement with recent studies where another GH3 $\beta$-glucosidase (Aspergillus niger $\beta$-glucosidase, a highly important cellulase) preferentially adsorbs to lignin [18,26,27].

\subsection{Influence of surfactant and temperature on the $\beta$-glucosidases adsorption to lignins}

Previous studies reported that nonionic surfactants could reduce enzyme adsorption because the hydrophobic portion of the surfactant binds to lignin $[26,28,29]$. Therefore, we examined the non-productive adsorption of $\beta$-glucosidases on the lignin preparations in the absence and presence of surfactant. Fig. 4 shows the adsorption of TpBGL1 and TpBGL3 to SL and EL preparations $(15 \mathrm{mg} / \mathrm{mL})$ in the absence and presence of surfactant Triton X-100 (TX) at $20^{\circ} \mathrm{C}$. For $\mathrm{TpBGL1}$, the most significant change was observed at $\mathrm{pH} 4$ (Fig. 4B), where the addition of $1 \% \mathrm{TX}$ reduced significantly the adsorption of TpBGL1 on the EL preparation (from $10 \%$ to about $50 \%$ ). Thus, suggesting that at $\mathrm{pH} 4$ the hydrophobic interactions play an important role in non-productive adsorption of TpBGL1 on the EL. The decrease in TpBGL1 adsorption at pH 4, therefore, was most likely due to the competitive adsorption of TX onto hydrophobic EL surface. For TpBGL3, at all pH values, the addition of $1 \% \mathrm{TX}$ also reduced the adsorption of TpBGL3 on the SL and EL preparations (Fig. 4C and D), which suggests that hydrophobic interactions also contribute to the non-productive adsorption of TpBGL3 on the lignins.

Previous studies showed that an increase of temperature resulted in an increase in the adsorption of cellulases onto lignins, probably due to increase of hydrophobic interactions [30-32]. Therefore, the effect of temperature on bacterial $\beta$-glucosidases adsorption to SL and EL preparations $(5 \mathrm{mg} / \mathrm{mL}$ ) were evaluated by performing the adsorption experiments at $20^{\circ} \mathrm{C}$ and $70^{\circ} \mathrm{C}$ (Fig. 5). For TpBGL1 and TpBGL3, similar adsorption profiles were observed at both temperatures.

\section{Discussion}

\subsection{TpBGL1 adsorption is electrostatically modulated}

Lignin adsorption is a major inhibitory mechanism of cellulases, xylanases, and $\beta$-glucosidases $[3,11]$. The enzyme adsorption 

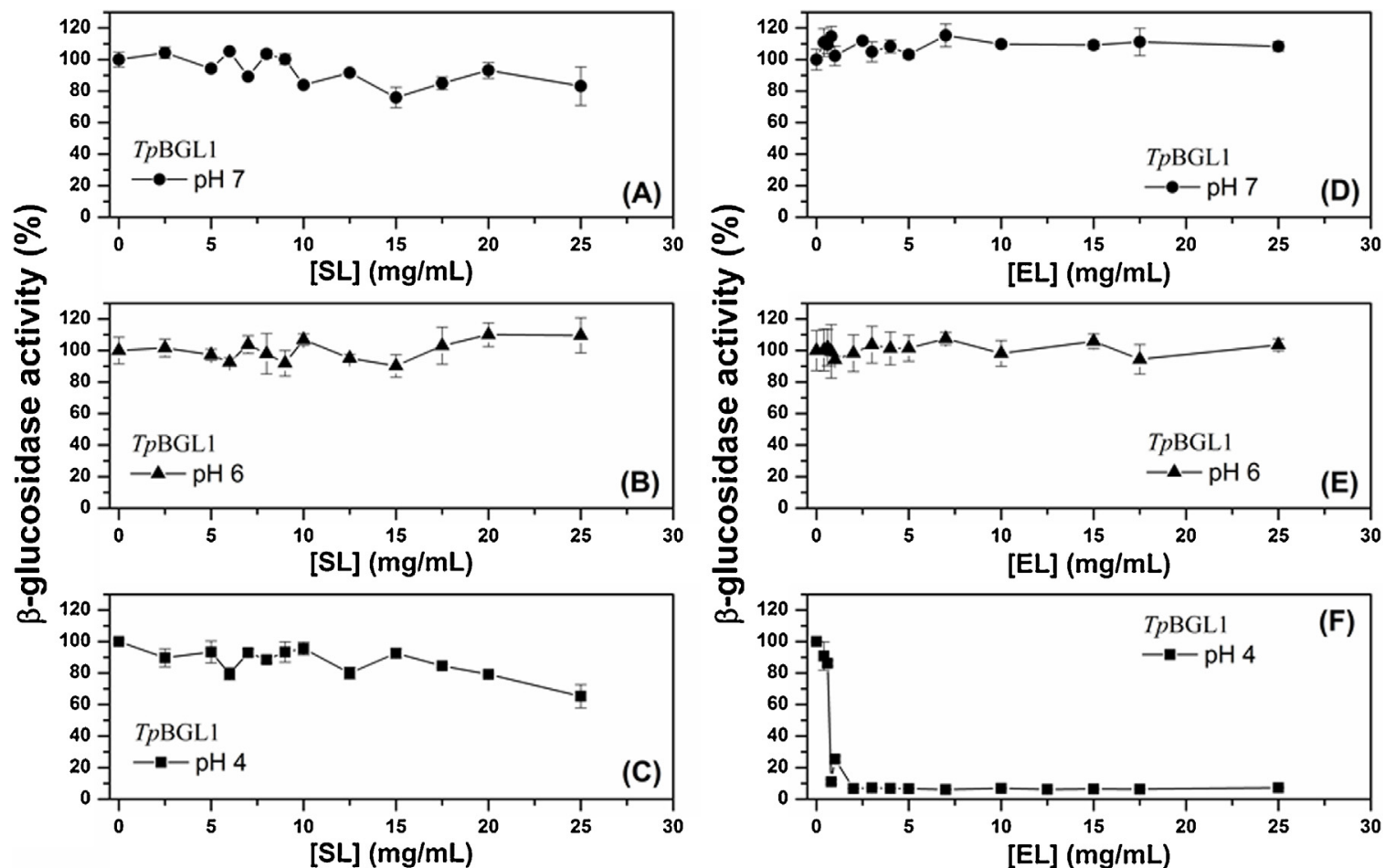

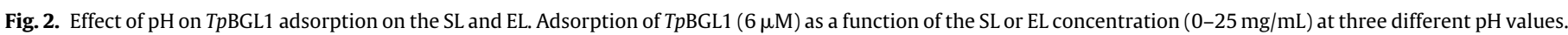
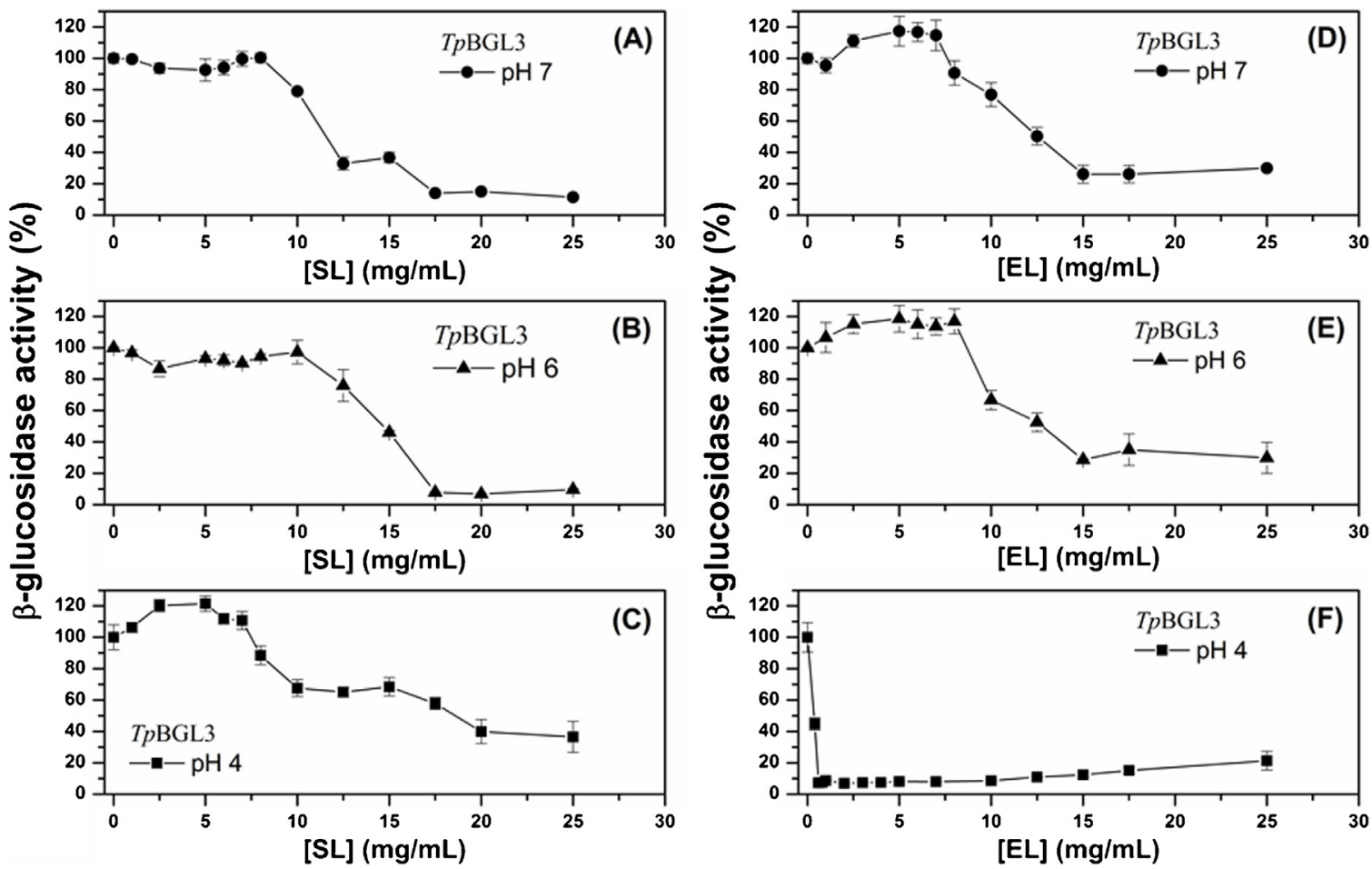

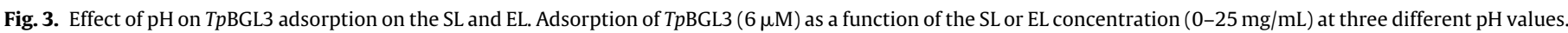

mechanism can be induced by electrostatic and hydrophobic interactions [4,11,26,33]. Furthermore, lignin sources affect enzyme adsorption using structural features and lignin composition [3]. TpBGL1 binding to SL and EL preparations were found to be strongly $\mathrm{pH}$-dependent, suggesting that electrostatic forces are involved in enzyme-lignins interactions (Fig. 2). In general, TpBGL1 binding decreased with increasing $\mathrm{pH}$ value. Both $\beta$-glucosidases were negatively charged at $\mathrm{pH} 7$ and 6 , while at $\mathrm{pH} 4$ the enzymes acquired positive charge (Fig. 1C). However, both lignin preparations were negatively charged in the entire $\mathrm{pH}$ range studied. Hence, very low TpBGL1 adsorption at pH 7 and 6 may be explained by repulsive electrostatic interactions between lignin preparations and TpBGL1 (Fig. 2). Furthermore, strong TpBGL1 adsorption at pH 4 may be explained by attractive electrostatic interactions between 

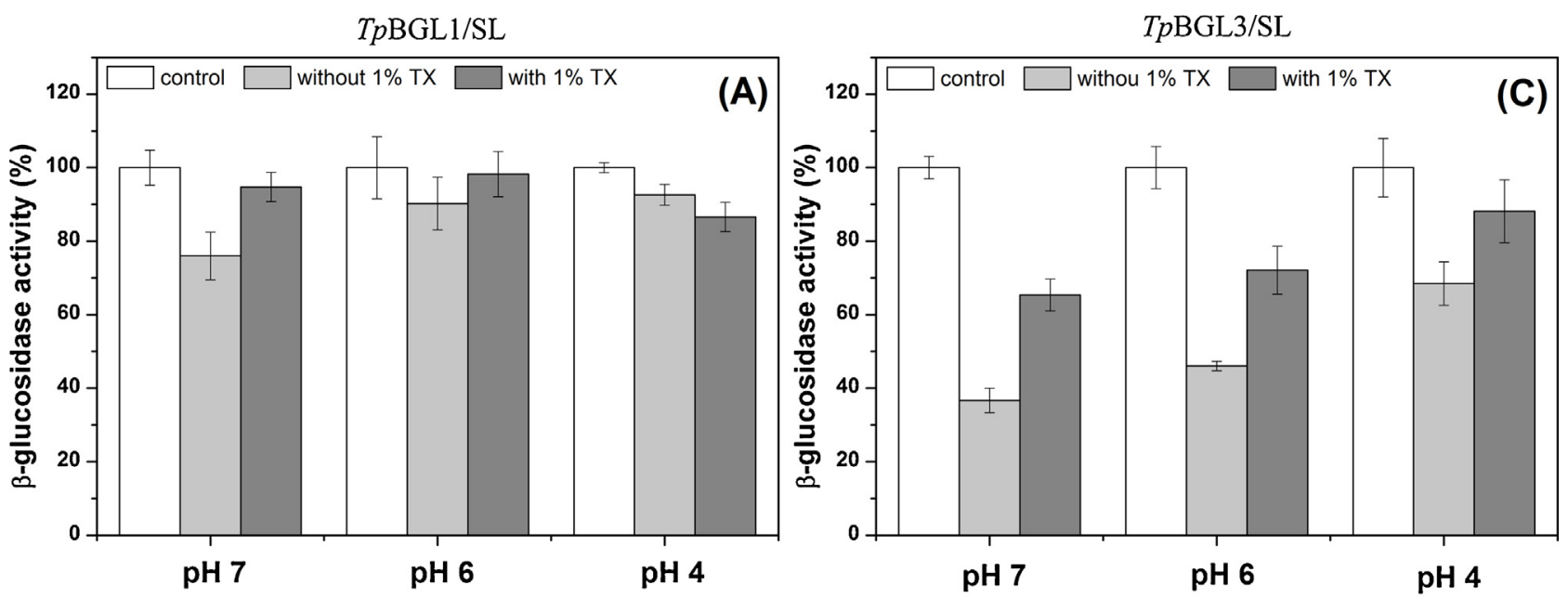

$T p$ BGL1/EL
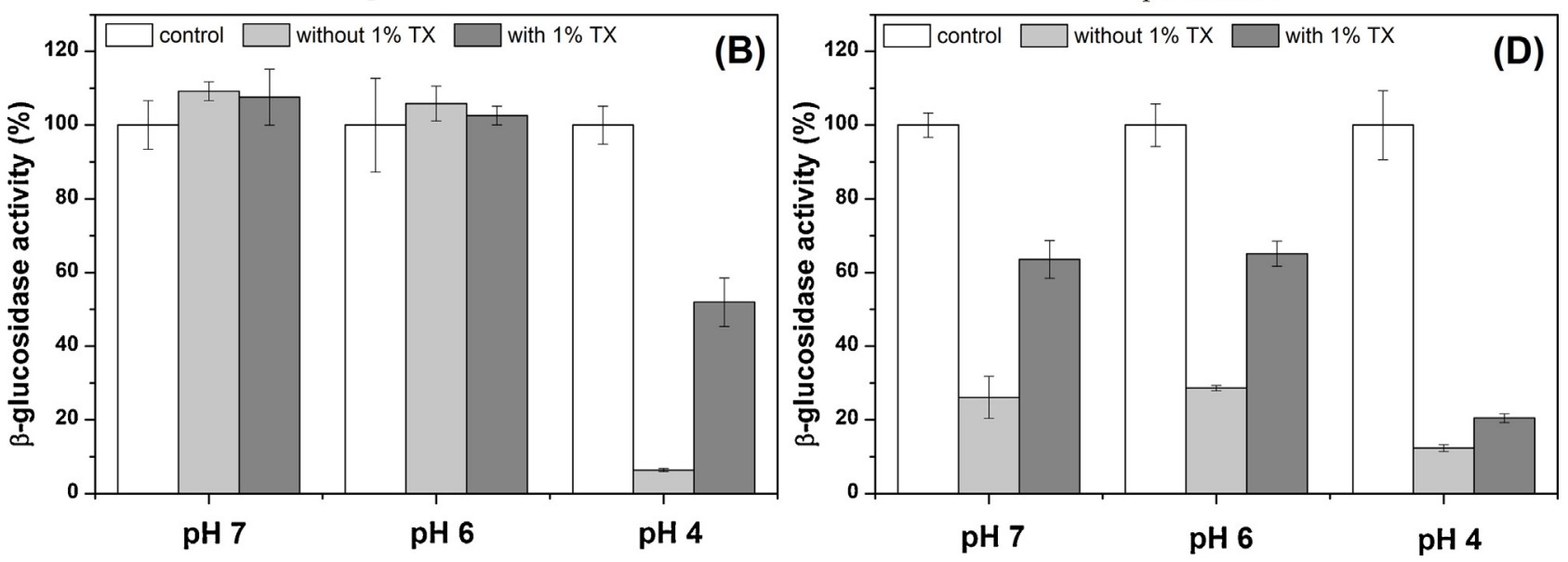

Fig. 4. Effect of surfactant (1\% Triton X-100) on TpBGL1 and TpBGL3 $(6 \mu \mathrm{M})$ adsorption on the lignin preparations (15 mg/mL).

lignin preparations (SL and EL) and TpBGL1 (Fig. 2C and F). At $\mathrm{pH} 4$, EL preparation is significantly more negative charged when compared to SL preparation (Fig. 1C). This difference may, at least partially, explain why more TpBGL1 was bound onto EL preparation.

\subsection{The C-terminal FnIII-like domain increases TpBGL3 adsorption}

The function of FnIII-like domain is not completely clear. Previous studies indicated that the position of this domain in the structure excludes its direct participation in the recognition of small substrates, however, it may be involved in the anchoring of the enzyme on large polymeric substrates, as well as, in thermo stabilization of the entire protein $[16,17]$. Besides, functional analysis of hybrid enzymes generated by FnIII-like domain shuffling confirms its role in cell wall adhesion [34]. Recently, Lima et al. suggested that FnIII-like domain from $A$. niger $\beta$-glucosidase is important for anchoring the domain to the lignin matrix [18]. The presence of the FnIII-like domain (Fig. 1B) indeed increased non-productive adsorption of $T p B G L 3$. At the entire $\mathrm{pH}$ range considered in this study, significantly more TpBGL3 than TpBGL1 was bound onto lignin preparations, both SL and EL (Figs. 2 and 3). The theoretical pI values determined for TpBGL3 $\Delta$ FnIII (catalytic domain, gray in Fig. 1B) and FnIII-like domain (black in Fig. 1B) are 5.1 and 8.7, respectively [19]. Thus, FnIII-like domain possibly acquires positive net charge in the entire $\mathrm{pH}$ range considered. On the contrary, TpBGL3 $\Delta$ FnIII possibly acquires negative charges at
pH 7 and 6, while at pH 4 acquires positive charge. Hence, it is likely that at pH 7 and 6, FnIII-like domain interacts with lignin preparations through electrostatic and hydrophobic interactions that can partially, or completely, overcome repulsive electrostatic forces between the catalytic domain (TpBGL3 $\Delta$ FnIII) and lignin preparations. At $\mathrm{pH} 4$, both TpBGL3 domains possibly acquire positive charges and adsorption may be explained mostly by attractive electrostatic interactions between the lignin preparations (SL and $\mathrm{EL}$ ) and TpBGL3. The data provided in this study are consistent with a model where electrostatic and hydrophobic interactions contribute to the adsorption mechanism of $\beta$-glucosidases, which is summarized in Fig. 6.

\subsection{Increase of temperature did not result in an increase in the adsorption of $\beta$-glucosidases onto lignins}

An increase in temperature may affect the structure of mesophilic enzymes leading to exposure of more hydrophobic regions to the solvent and, therefore, enhancing the hydrophobic interactions [30-32]. However, it was recently shown that there were no significant changes in the secondary, tertiary and quaternary structures of the hyperthermophilic bacterial $\beta$-glucosidases TpBGL1 and TpBGL3 for temperatures below $80^{\circ} \mathrm{C}$ [13]. Thus, probably even at $70^{\circ} \mathrm{C}$ there is no significant increase in hydrophobic regions on $\beta$-glucosidases structures exposed to the solvent. This could explain why an increase in temperature from $20^{\circ} \mathrm{C}$ to 

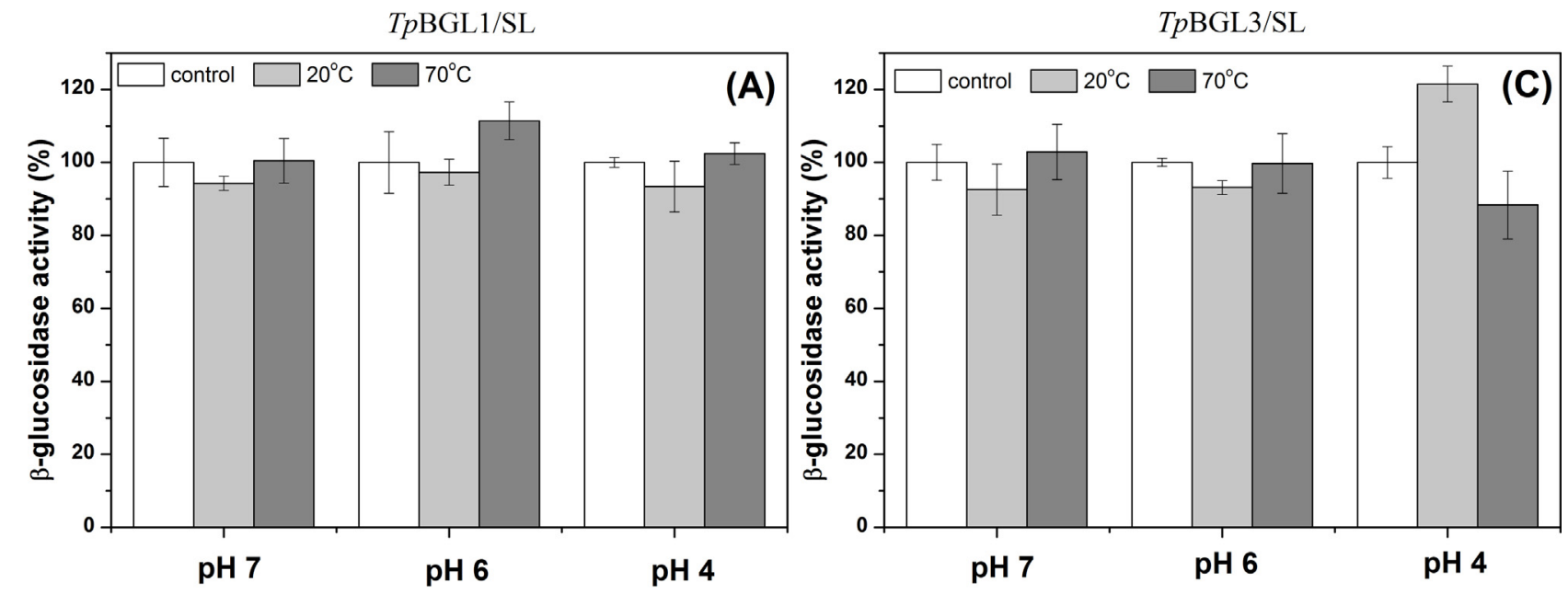

$T p \mathrm{BGL} 1 / \mathrm{EL}$
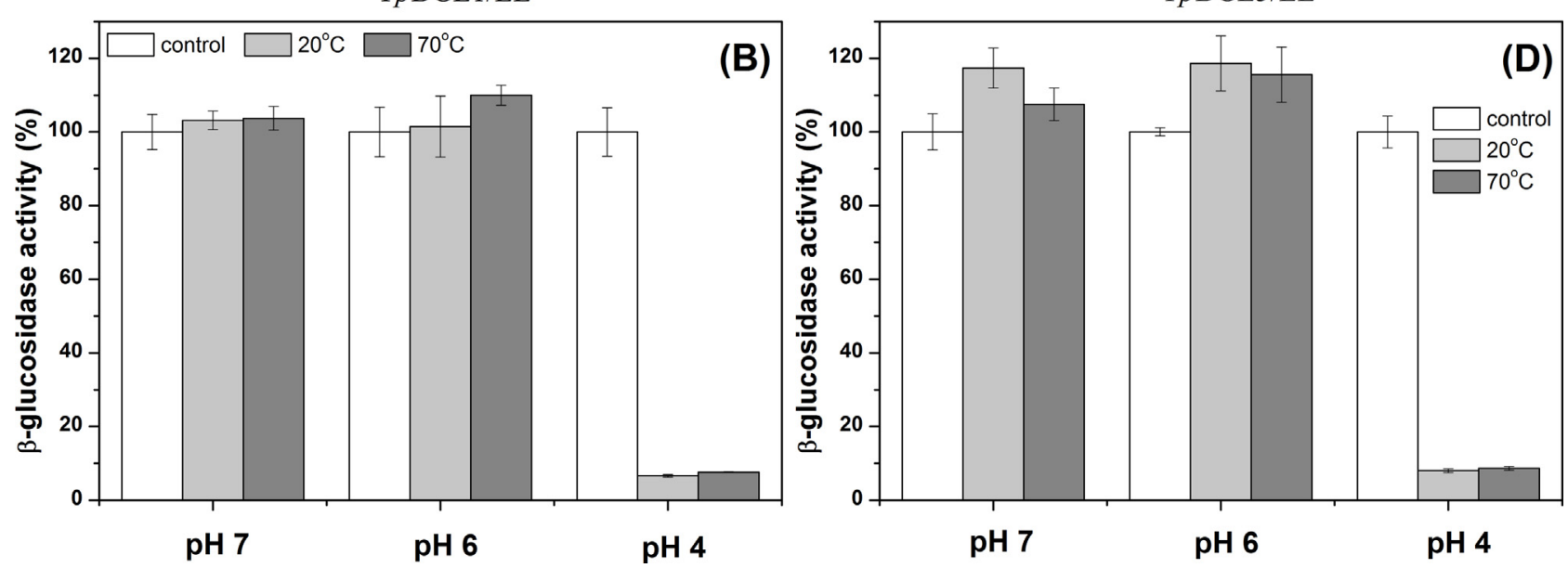

Fig. 5. Effect of temperature $\left(20^{\circ} \mathrm{C}\right.$ and $\left.70^{\circ} \mathrm{C}\right)$ on $T p B G L 1$ and $T p B G L 3(6 \mu \mathrm{M})$ adsorption on the lignin preparations $(5 \mathrm{mg} / \mathrm{mL})$.
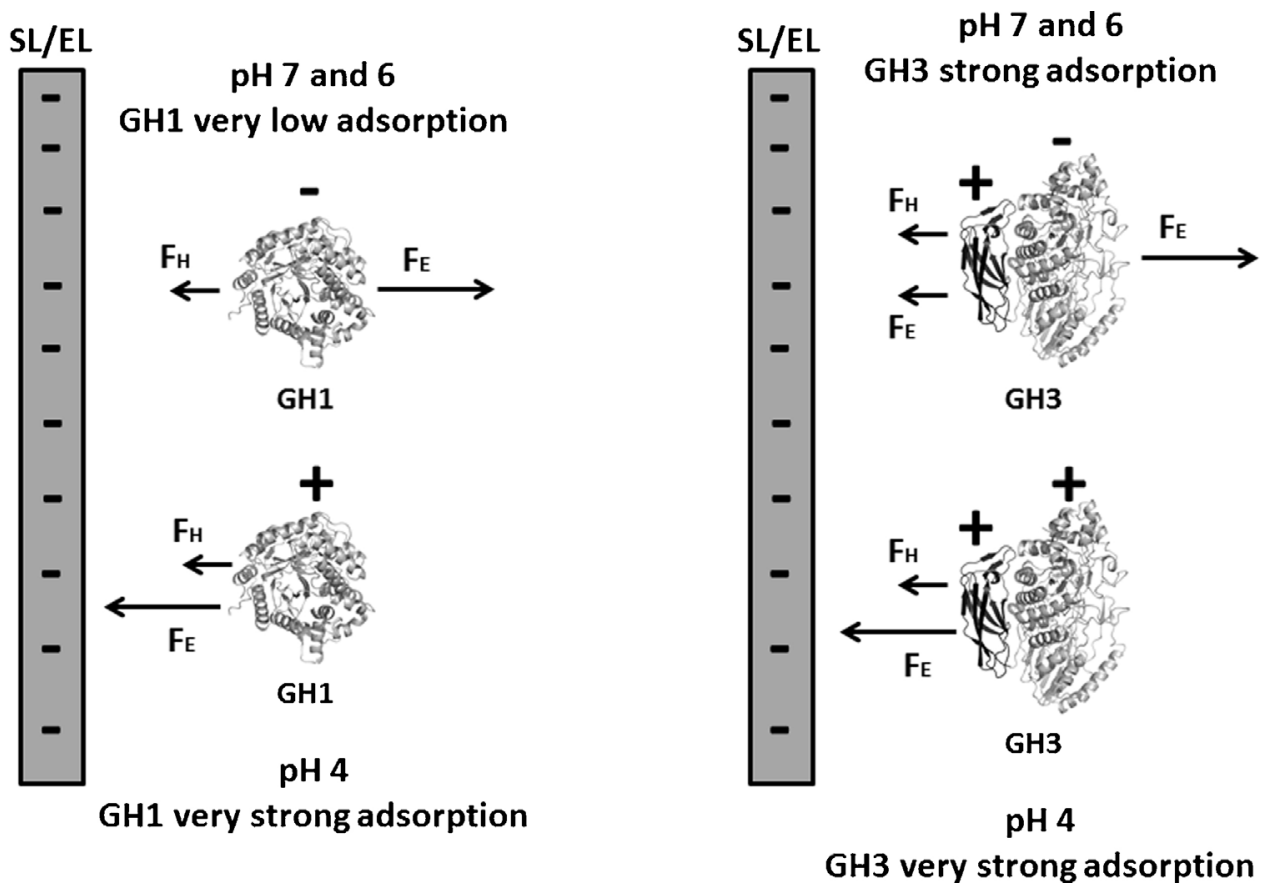

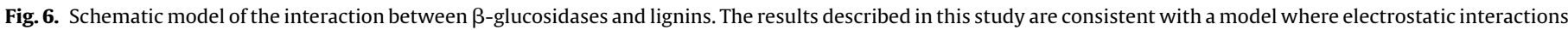
strongly contribute to the adsorption mechanism. $\mathrm{F}_{\mathrm{E}}$ : electrostatic force. $\mathrm{F}_{\mathrm{H}}$ : hydrophobic force. 
$70^{\circ} \mathrm{C}$ did not result in a significant change in the fraction of $\beta$ glucosidases adsorbed to the SL and EL preparations (Fig. 5).

\subsection{TpBGL1 can be recycled via the liquid phase at $p H$ of optimum activity}

A recent study reported that $T p B G L 1$ reached its optimum activity within the $\mathrm{pH}$ range of $6-7$, while TpBGL3 reached its optimum activity around $\mathrm{pH} 4$ [12]. At all $\mathrm{pH}$ values, attractive electrostatic interactions strengthen the non-productive adsorption of TpBGL3. Furthermore, the higher adsorption was observed at $\mathrm{pH} 4$, condition where TpBGL3 reaches its optimum activity. However, at pH 7 and 6 , electrostatic repulsion weakens the non-productive adsorption of TpBGL1 to lignins, conditions where TpBGL1 reaches its optimum activity. Therefore, the results indicate that TpBGL1 could be recycled via the liquid phase at $\mathrm{pH}$ where its activity is maximum.

\section{Conclusions}

In conclusion, the data showed that $\beta$-glucosidases can adsorb to lignins through different mechanisms. TpBGL1 adsorption onto lignins was found to be strongly $\mathrm{pH}$-dependent, suggesting that the adsorption is electrostatically modulated. For TpBGL3, the results suggest that FnIII-like domain interacts with lignins through electrostatic and hydrophobic interactions that can partially, or completely, overcome repulsive electrostatic forces between the catalytic domain and lignins. Finally, the increase of temperature did not result in the increase of $\beta$-glucosidases adsorption, probably because there is no significant increase in hydrophobic regions in the $\beta$-glucosidases structures. These studies can be useful in the field of plant structural polysaccharides conversion into bioenergy.

\section{Funding}

This study was funded by Fundação de Amparo à Pesquisa do Estado de São Paulo (FAPESP) via grants\# 2015/02897-3, and fellowship\# 2014/02065-5 (VMS).

\section{Conflict of interest}

The authors declare that they have no conflict of interest. This article does not contain any studies with human participants or animals performed by any of the authors.

\section{Author contributions}

VMS, ASS: carried out the production and purification of TpBGL1 and TpBGL3. DN, MON: carried out the isolation of lignin preparations. VMS, ASS, WG: carried out the experiments. WG: coordinated the overall study, and contributed to the analysis of the results and finalizing the paper. VMS, ASS, DN, MON, JRCM, FMC, IP, WG: all authors suggested modifications to the draft and approved the final manuscript.

\section{Acknowledgment}

We thank the Central Experimental Multiusuário (CEM/UFABC) for technical assistance.

\section{Appendix A. Supplementary data}

Supplementary data associated with this article can be found, in the online version, at http://dx.doi.org/10.1016/j.enzmictec.2016. 02.007 .

\section{References}

[1] W.H. Zyl, S.H. Rose, K. Trollope, J.F. Görgens, Fungal $\beta$-mannanases: mannan hydrolysis, heterologous production and biotechnological applications, Process Biochem. 45 (2010) 1203-1213.

[2] C.A. Rezende, M.A. Lima, P. Maziero, E.R. Deazevedo, W. Garcia, I. Polikarpov, Chemical and morphological characterization of sugarcane bagasse submitted to a delignification process for enhanced enzymatic digestibility, Biotechnol. Biofuels 4 (2011) 54

[3] F. Guo, W. Shi, S. Sun, X. Li, F. Wang, J. Zhao, Y. Qu, Differences in the adsorption of enzymes onto lignins from diverse types of lignocellulosic biomass and the underlying mechanism, Biotechnol. Biofuels 7 (2014) 38.

[4] C. Qin, K. Clarke, K. Li, Interactive forces between lignin and cellulase as determined by atomic force microscopy, Biotechnol. Biofuels 7 (2014) 65.

[5] N. Mosier, C. Wyman, B. Dale, R. Elander, Y.Y. Lee, M. Holtzapple, M. Ladisch, Features of promising technologies for pretreatment of lignocellulosic biomass, Bioresour. Technol. 96 (2005) 673-686.

[6] R. Kumar, S. Singh, O.V. Singh, Bioconversion of lignocellulosic biomass: biochemical and molecular perspectives, J. Ind. Microbiol. Biotechnol. 35 (2008) 377-391.

[7] P. Kumar, D.M. Barrett, M. Delwiche, P. Stroeve, Methods for pretreatment of lignocellulosic biomass for efficient hydrolysis and biofuel production, Ind. Eng. Chem. Res. 48 (2009) 3713-3729.

[8] L.R. Lynd, P.J. Weimer, W.H. van Zyl, I.S. Pretorius, Microbial cellulose utilization: fundamentals and biotechnology, Microbiol. Mol. Biol. Rev. 66 (2002) 506-577.

[9] F. Colussi, W. Garcia, F.R. Rosseto, B.L.S. Mello, M. Oliveira Neto, I. Polikarpov, Effect of $\mathrm{pH}$ and temperature on the global compactness structure, and activity of cellobiohydrolase Cel7A from Trichoderma harzianum, Eur. Biophys. J. 41 (2012) 89-98

[10] A. Sørensen, M. Lübeck, P.S. Lübeck, B.K. Ahring, Fungal $\beta$-glucosidases: a bottleneck in industrial use of lignocellulosic materials, Biomolecules 3 (2013) 612-631.

[11] A. Berlin, M. Balakshin, N. Gilkes, J. Kadla, V Maximenko, S. Kubo, J Saddler, Inhibition of cellulase, xylanase and $\beta$-glucosidase activities by softwood lignin preparations, J. Biotechnol. 125 (2006) 198-209.

[12] J. Cota, T.L.R. Corrêa, A.R.L. Damásio, J.A. Diogo, Z.B. Hoffmam, W. Garcia, L.C. Oliveira, R.A. Prade, F.M. Squina, Comparative analysis of three hyperthermophilic GH1 and GH3 family members with industrial, New Biotechnol. 32 (2015) 13-20

[13] F. Colussi, V.M. Silva, I. Miller, J. Cota, L.C. Oliveira, M. Oliveira Neto, F.M. Squina, W. Garcia, Oligomeric state and structural stability of two hyperthermophilic $\beta$-glucosidases from Thermotoga petrophila, Amino Acids 47 (2015) 937-948.

[14] D.L. Zechel, A.B. Boraston, T.M. Gloster, C.M. Boraston, J.M. Macdonald, D.M. Tibrook, R.V. Stick, G.J. Davies, Iminosugar glycosidase inhibitors: structural and thermodynamic dissection of the binding of isofagomine and 1-deoxynojirimycin to $\beta$-glucosidases, J. Am. Chem. Soc. 125 (2003) 14313-14323.

[15] J.R.K. Cairns, A. Esen, ß-Glucosidases, Cell. Mol. Life Sci. 67 (2010) 3389-3405.

[16] T. Pozzo, J.L. Pasten, E.N. Karlsson, D.T. Logan, Structural and functional analyses of $\beta$-glucosidase 3B from Thermotoga neapolitana: a thermostable three-domain representative of glycoside hydrolase 3, J. Mol. Biol. 397 (2010) 724-739.

[17] R.P. McAndrew, J.I. Park, R.A. Heins, W. Reindl, G.D. Friedland, P. Díhaeseleer, T. Northen, K.L. Sale, B.A. Simmons, P.D. Adams, From soil to structure, a nove dimeric $\beta$-glucosidase belonging to glycoside hydrolase family 3 isolated from compost using metagenomic analysis, J. Biol. Chem. 288 (2013) 14985-14992.

[18] M.A. Lima, M. Oliveira Neto, M.A.S. Kadowaki, F.R. Rosseto, E.T. Prates, F.M Squina, A.F.P. Leme, M.S. Skaf, I. Polikarpov, Aspergillus niger $\beta$-glucosidase has a celulase-like tadpole molecular shape, insights into glycoside hydrolase family 3 (GH3) $\beta$-glucosidase structure and function, J. Biol. Chem. 288 (2013) 32991-33005.

[19] E. Gasteiger, C. Hoogland, A. Gattiker, S. Duvaud, M.R. Wilkins, R.D. Appel, A. Bairoch, Protein identification and analysis tools on the ExPASy server, in: John M. Walker (Ed.), The Proteomics Protocols Handbook, Humana Press, 2005, pp. 571-607.

[20] A. Abächerli, F. Doppenberg, Method for preparing alkaline solutions containing aromatic polymers, US Patent (2001) US6239198 B1.

[21] B. Jachimska, M. Wasilewska, Z. Adamczyk, Characterization of globular protein solutions by dynamic light scattering, electrophoretic mobility, and viscosity measurements, Langmuir 24 (2008) 6866-6872.

[22] M.M. Bradford, A rapid and sensitive method for the quantitation of microgram quantities of protein utilizing the principle of protein-dye binding, Anal. Biochem. 72 (1976) 248-254.

[23] G.L. Miller, Use of dinitrosalicylic acid reagent for determination of reducing sugar, Anal. Chem. 31 (1959) 426-428.

[24] Z. Wang, J. Zhu, Y. Fu, M. Qin, Z. Shao, J. Jiang, F. Yang, Lignosulfonate-mediated cellulase adsorption: enhanced enzymatic saccharification of lignocellulose through weakening nonproductive binding to lignin, Biotechnol. Biofuels 6 (2013) 156

[25] Ł. Klapiszewski, M. Nowacka, G. Milczarek, T. Jesionowski, Physicochemical and electrokinetic properties of silica/lignin biocomposites, Carbohydr. Polym. 94 (2013) 345-355. 
[26] M. Haven, H. Jørgensen, Adsorption of $\beta$-glucosidases in two commercial preparations onto pretreated biomass and lignin, Biotechnol. Biofuels 6 (2013) 165.

[27] D.W. Sammond, J.M. Yarbrough, E. Mansfield, Y.J. Bomble, S.E. Hobdey, S.R. Decker, L.E. Taylor, M.G. Resch, J.J. Bozell, M.E. Himmel, T.B. Vinzant, M.F. Crowley, Predicting enzyme adsorption to lignin films by calculating enzyme surface hydrophobicity, J. Biol. Chem. 289 (2014) 20960-20969.

[28] T. Eriksson, J. Börjesson, F. Tjerneld, Mechanism of surfactant effect in enzymatic hydrolysis of lignocellulose, Enzyme Microb. Technol. 31 (2002) 353-364.

[29] J.B. Kristen, J. Börjesson, M.H. Bruun, F. Tjerneld, H. Jørgensen, Use of surface active additives in enzymatic hydrolysis of wheat straw lignocellulose, Enzyme Microb. Technol. 40 (2007) 888-895.

[30] Q.Q. Wang, J.Y. Zhu, C.G. Hunt, H.Y. Zhan, Kinetics of adsorption desorption, and re-adsorption of a commercial endoglucanase in lignocellulosic suspensions, Biotechnol. Bioeng. 109 (2012) 1965-1975.

[31] N. Pareek, T. Gillgren, L.J. Jönsson, Adsorption of proteins involved in hydrolysis of lignocellulose on lignins and hemicelluloses, Bioresour. Technol. 148 (2013) 70-77.
[32] D.L. Machado, J. Moreira, J.G.C. Pradella, A. Bonomi, S.C. Rabelo, A.C. Costa, Adsorption characteristics of cellulase and $\beta$-glucosidase on Avicel pretreated sugarcane bagasse, and lignin, Biotechnol. Appl. Biochem. 62 (2015) 681-689.

[33] J.L. Rahikainen, J.D. Evans, S. Mikander, A. Kalliola, Cellulase-lignin interactions-the role of carbohydrate-binding module and $\mathrm{pH}$ in non-productive binding, Enzyme Microb. Technol. 53 (2013) 315-321.

[34] J. Marín-Navarro, L. Gurgu, S. Alamar, J. Polaina, Structural and functional analysis of hybrid enzymes generated by domain shuffling between Saccharomyces cerevisiae (var. diastaticus) Sta1 glucoamylase and Saccharomycopsis fibuligera Bgl1 $\beta$-glucosidase, Appl. Microbiol. Biotechnol. 89 (2011) 121-130.

[35] K. Arnold, L. Bordoli, J. Kopp, T. Schwede, The Swiss-model workspace: a web-based environment for protein structure homology modelling, Bioinformatics 22 (2006) 195-201. 